\title{
"Vamos, déjese querer". Afecto, emociones y red en cartas de escritores rioplatenses (1837-1852)
}

Natalia Crespo

UBA-Conicet

\section{Resumen}

Este artículo indaga los usos/gestos del afecto y la dinámica de la "comunidad emocional" (Rosenwein) generada entre algunos de los intelectuales románticos de la Generación de 1837 en un corpus de cuarenta cartas que se intercambiaron durante su exilio (1837 a 1852), incluidas en el Archivo del Dr. Juan María Gutiérrez). A partir de algunas nociones del llamado "giro afectivo" (Ahmed, Rosenwein, Arfuch, Macón, Peluffo) y teniendo en cuenta el concepto de redes intelectuales (Maíz, Fernández Bravo), este artículo analiza el prestigio que van adquiriendo determinados sentimientos y las posiciones diferenciales que cada intelectual va ocupando dentro del grupo. La construcción de alianzas homosentimentales, la estetización del dolor del exilio, el recíproco control y estímulo literario son algunas de las recurrencias en este corpus de escrituras privadas pero sociales que, aunque de narradores célebres (Juan María Gutiérrez, Esteban Echeverría, José Mármol, Domingo F. Sarmiento), permanecen aún hoy poco transitadas.

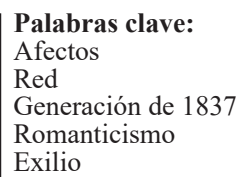

\begin{abstract}
This article investigates the uses/gestures of affect and the dynamics of the "emotional community" (Rosenwein) in forty letters - included in the Archivo del Dr.Juan Maria Gutierrez - written by some of the Romantic intellectuals from the known "Generación de 1837" during their exiles (1837-1852). Taking into account some theoretical notions from the so-called "affective turn" (Ahmed, Rosenwein, Arfuch, Macón, Peluffo), and considering as well the concept of intellectual net (Maíz, Fernández Bravo), this paper analyzes which sentiments have become prestigious within this group and which roles, within a dynamic and systemic notion of the "emotional community", have been occupied by these members. The construction of certain homo-erotic alliances, the expression of nostalgia as something aesthetic, and the reciprocal control among these intellectuals are some of the recurrences
\end{abstract}


that can be read in these pieces of intimate but social writing. Although composed by famous Romantic writers from this period (such as Juan María Gutiérrez, Esteban Echeverría, José Mármol, Domingo F. Sarmiento), these letters have received only few critical readings so far.

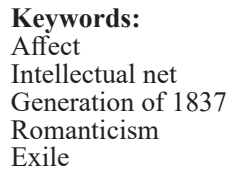

\section{Introducción}

En el capítulo 7 de En clave emocional, Ana Peluffo ensaya una lectura afectiva del Martín Fierro y hace hincapié en dos aspectos del poema: "la formación de nuevos discursos de la masculinidad a partir de la figura del gaucho que llora y, por otro lado, la construcción de alianzas homosentimentales en las que se recurre a la estetización de la compasión como forma de negociación identitaria en el espacio de la frontera" (Peluffo, 2016: 143). Ahora bien, ¿se trata de "nuevos discursos de la masculinidad"? Las alianzas homosentimentales, la estetización de la compasión, ¿no existían ya entre los miembros de la Generación de 1837, bajo otras matrices de expresión? ¿Cómo se han conjugado en los letrados rioplatenses de las décadas de 1830 y 1840 la sensibilidad romántica, los modelos de masculinidad y los vínculos afectivos?

Partiendo del concepto de "comunidad emocional" (Rosenwein) y de la idea de red intelectual (Maíz, Fernández Bravo), este artículo revisa la representación de lo afectivo/emocional (Ahmed, Macón) en un corpus de cuarenta cartas privadas escritas (casi todas) entre 1837 y 1852, intercambiadas por algunos intelectuales proscriptos durante el rosismo e incluidas en el Epistolario del Dr. Juan María Gutiérrez. ${ }^{1}$ Me interesa rastrear qué afectos/sentimientos son prestigiosos para este grupo de literatos y cómo los expresan, cómo se van gestando los roles diferenciales e interdependientes (desde el punto de vista sistémico de red) de cada miembro de esa comunidad emocional y qué significados cobra lo afectivo en esas cartas. Creemos que la lectura de estas piezas - de prosa íntima y, a la vez, social, aún poco transitadas por la crítica desde un marco teórico de los afectos ${ }^{-2}$, puede ser un pequeño aporte al cuestionamiento de ciertas dicotomías cuya rigidez, siguiendo a Peluffo, signó durante las últimas décadas los estudios de nuestra literatura decimonónica. ${ }^{3}$ Las fronteras que, según

1 Recorto, del amplio conjunto de epístolas reunidas en los siete tomos del Epistolario, aquellas escritas durante el exilio porque considero que son las que mejor dejan ver la intensidad emocional de estos vínculos: fechadas entre el año de partida de casi todos ellos, 1837, y el año de la caída de Rosas, 1852 , resultan miradores privilegiados para acercarse a lo sentimental.

2 Para Viñas (1974), "existe un género fundamental en ese momento que era la correspondencia. Generalmente suele ser deslumbrante. Frente a la censura victoriana, en la correspondencia se decían cosas que no aparecen en otro lado". Un artículo pionero en el estudio de estas cartas es el hermoso texto de Cristina Iglesia, 'Contingencias de la intimidad...'”. Quien más ha trabajado hasta el momento en torno al "discurso epistolar de grandes ensayistas políticos de la Organización Nacional"m desde un punto de vista de análisis del discurso y de la crítica genética, es Lucila Pagliai (2013: 13-22). Por su parte, Graciela Batticuore ha abordado en detalle una de las cartas que Mercedes Marín del Solar, poeta chilena, le dirige a Juan María Gutiérrez en 1846 con motivo de la América Poética. Esta crítica analiza las manifestaciones de lo que denomina "autoría atenuada" en esta prosa epistolar: la exhibición del pudor, el saber callar, la vergüenza, como gestos que estructuran esta carta, incluida en el Archivo Epistolario del Dr. Juan María Gutiérrez (Batticuore, 2005: 112-176). Adriana Amante (2010), tanto en su libro sobre los exilios a Brasil como en algunos artículos posteriores, también ha analizado partes de este epistolario.

3 "En los últimos años, nos hemos acostumbrado a leer el siglo XIX a partir del debate sobre la construcción y modernización de las naciones. Dentro de esta conversación, se privilegió el lado racionalmente afiliativo de los imaginarios nacionales en detrimento de su componente emocional" (Peluffo, 2016:16). Se trata de un siglo que "hasta ahora ha sido leído casi exclusivamente desde las ideologías de la civilización, la modernidad y el progreso. ¿De qué manera las emociones desestabilizan el bino- 
ha pretendido la episteme moderna, separarían en compartimentos estancos lo público de lo privado, el cuerpo de la mente, el pensamiento de la acción, una mentada racionalidad masculina frente a la atribuida pasión femenina, se revelan difusas, cuando no inexistentes en estas cartas. También, estas permiten ver hasta qué punto el desarrollo de gran parte de la literatura de la Generación de 1837 es inseparable de los vínculos afectivos que sostuvieron entre sí sus integrantes, de la situación de exilio y de las dificultades materiales de la vida cotidiana de la época.

Varios autores han marcado ya (Weimberg, Wasserman, Janik) de qué modo -así como la generación de los "clásicos" o "rivadavianos" se encargó de independizar al país del yugo español - sus hijos, "los románticos" del 37, se adjudicaron la misión de afianzar culturalmente los triunfos de la Revolución de Mayo. Mejorar las costumbres y la moral, "fundar" una cultura nacional, "educar al soberano" fueron los objetivos por los que abogaron estos intelectuales en pos del plan civilizatorio. Influidos por las ideas y lecturas de la Ilustración y por las diversas corrientes europeas del Romanticismo y del socialismo (Tarcus, 2016), escribieron lo que Hugo Achugar et al. (1998: 39-77) llamaron "los parnasos fundacionales": obras que definirían performativamente - es decir, que al definirlo lo constituyeron - aquello más tarde considerado "la literatura nacional", epítome de la esencia americana y/o argentina.

El año 1837 marca un punto de quiebre en la historia de Buenos Aires: el régimen del entonces gobernador de las Provincias Unidas del Río de la Plata, Juan Manuel de Rosas, recrudece su sistema represor. Un grupo de jóvenes intelectuales funda el Salón Literario: Juan María Gutiérrez, Juan Bautista Alberdi, Esteban Echeverría, José Mármol, Domingo F: Sarmiento, Félix Frías, Luis Domínguez, entre otros, se reúnen en el gabinete de lectura de Marcos Sastre, dos o tres veces por semana, para compartir lecturas y discusiones literarias y políticas (Weimberg, 1977). El Salón Literario representa una de las primeras formas de sociabilidad moderna en Buenos Aires. Se trata de "una sociabilidad estudiantil, nacida de los lazos específicos con una clase de edad" - jóvenes de, en promedio, veintitrés años-y "un nivel de cultura" (el 90\% eran egresados o estudiantes de la Universidad de Buenos Aires) que "trama a su alrededor todo un mundo de nuevas relaciones: la igualdad de los intercambios, la libertad de expresión, la comunión en y por el intercambio de ideas" (González Bernaldo de Quirós, 2008: 117). "Fueron estos excéntricos", escribe Tarcus sobre los románticos de 1837, "los primeros en hablar en el Río de la Plata contra los efectos negativos del individualismo posesivo y a favor del socialismo, en enarbolar un programa democrático radical que comprendía el asociacionismo civil (el mutualismo, el cooperativismo, el sindicalismo)..." (Tarcus, 2016: 70-71).

En los años siguientes, y a raíz de las persecuciones políticas, este grupo se dispersa en diferentes países del continente. Los destinos más frecuentes son Montevideo y Chile, pero también hay quienes huyen a Brasil, Bolivia o Europa. Desde sus nuevos hogares (siempre cambiantes), escriben cartas desesperadas a sus amigos y familiares: para dar cuenta de sus nuevas vidas, para sostener la lucha política, para hacer encargos bibliográficos y, al mismo tiempo, para expresar y ratificarse el afecto.

Años más tarde, al regresar al país, varios de estos intelectuales ocuparían cargos institucionales y devendrían figuras orgánicas del Estado-nación (para convertirse, con el correr del tiempo y de la historiografía, en figuras célebres y próceres). ${ }^{4}$ Publicistas, docentes, poetas, historiadores, agrimensores o abogados, en sus años de juventud se ganaban la vida como podían y escribían, además de obras literarias mio civilización-barbarie? ¿De qué modo los artefactos culturales interactúan con las constelaciones emocionales normativas dentro de las que surgen y a las que tratan de moldear? (Peluffo, 2016: 26). 4 "Cuando buena parte de la Generación de 1837 retornó a la Argentina de su exilio uruguayo o chileno, muchos de sus miembros se constituyeron en figuras prominentes de la elite y devinieron encumbrados hombres de Estado." (Tarcus, 2016: 84) 
y periodísticas, innumerables cartas. ¿De qué hablan allí? De la efusividad del cariño, de los dolores del exilio y de las quejas de soledad (a tono con la concepción romántica del individuo), 5 las "políticas de la amistad", 6 la nostalgia por la patria, el odio a Rosas, el deseo de escritura, el pedido de libros, la necesidad de dinero y el ejercicio de la labor intelectual: todos estos temas recurren en estas cartas, inseparables y desjerarquizados. Claro que, dentro de los temas comunes a todos ellos, y como parte de la dinámica propia de una red, cada autor toma una determinada posición en el grupo. A Juan María Gutiérrez parece asediarlo la urgencia por gestar proyectos colectivos que den entidad cultural propia a "lo americano". ${ }^{7}$ Se diría que es el único que antepone lo grupal por sobre lo personal. En el extremo opuesto, Echeverría suele escribir sobre sus propios malestares anímicos o, con tono asertivo, sobre su misión como poeta - de él dirá Florencio Varela que posee "tanto amor propio" (T. I: 182)-. A Sarmiento parece interesarle, ante todo, difundir su Facundo y hacer política, mientras que a Varela lo desvelan su periódico, su imprenta y su biblioteca. ${ }^{8}$ Cada carta deja ver, junto con determinado clima de época, las preocupaciones personales de cada autor, las particularidades de su voz y, a veces también, sus silencios. No es por fuera de ese magma de sentidos lábil y contingente que es el archivo epistolar -aunque no solo en virtud de él ${ }^{-9}$ que surgieron obras como Cantos del peregrino, de Mármol, Dogma socialista y El ángel caído, de Echeverría o la antología América Poética que compila Gutiérrez.

\section{Afectos, comunidad emocional y red intelectual}

Según Sara Ahmed, "los afectos son aquello que une, sostiene o preserva la conexión entre ideas, valores y objetos" (Ahmed, 2010: 29). No se trata de estados psicológicos individuales sino de prácticas sociales y culturales que manifiestan la sensibilidad matriz de una época o una determinada "estructura del sentir". ${ }^{10}$ "Sociales, inestables, dinámicos, paradójicos, los afectos así presentados” —explica Cecilia Macón, una de las pocas estudiosas argentinas del "giro afectivo" - constituyen una lógica capaz de dar cuenta del lazo social" (2013: 10). Los afectos son pensados - en analogía con los

5 "Con el romanticismo nace la idea contemporánea del individuo, radicalmente solo frente a la multitud de otros seres tan solos como él [...]. Con él surge la idea de un arte cuya misión es trascender las fronteras de lo real, erigiéndose en crítica de lo existente y en promesa de una trasformación futura de la naturaleza humana - un arte cuya asunción de esa misión mesiánica está predicada precisamente sobre la base de esa nueva conciencia de la radical individualidad del yo moderno." (Myers, 2005: 16). 6 En su libro así titulado (1998), Jacques Derrida propone pensar la amistad como un vínculo coyuntural, desigual, estratégico, dado entre dos sujetos que buscan, ante todo, una instancia de alianza ante un enemigo común, la gestación (o imaginación) de una red política afectiva que deviene -como la hospitalidad - un horizonte ético a alcanzar ( $\mathrm{y}$, a la vez, inalcanzable) más que una realidad concreta. Estas cartas podrían leerse a partir del concepto de "políticas de la amistad".

7 Este interés de Gutiérrez puede pensarse como manifestación del afán historicista romántico propio de esta generación (Wasserman, 2008). Analizo dicho interés en "La trama epistolar de la América Poética".

8 Me detengo en la correspondencia Varela-Gutiérrez en mi artículo “Un corazón porteño...” (2018: 199-219).

9 Varios autores han estudiado las múltiples influencias filosóficas que alimentaron los principales escritos de esta generación. Sin embargo, para comprender la complejidad de esta primera generación de intelectuales románticos socialistas no basta con trazar esa génesis, pues no solo de ideas filosóficas se nutrieron sus textos. "[L]o que interesa aquí", propone Tarcus, "son los usos efectivos que los jóvenes de 1837 hicieron de ciertas nociones y conceptos de Saint-Simon, Leroux, Mazzini o Lamennais para construir su propio lenguaje político intelectual que les permitiera pensar y operar sobre la sociedad rioplatense de su tiempo. [...]. Los receptores no copian: toman, seleccionan y utilizan conforme a las necesidades de construir su propio programa político" (Tarcus, 2016: 69-70). La comprensión de la multiplicidad de factores que convergieron en esas producciones permite, tal vez, revalorizar la importancia de los contextos de producción, del saber situado de cada obra.

10 "Las estructuras del sentir pueden ser definidas como experiencias sociales en solución, a diferencia de otras formaciones semánticas sociales que han sido precipitadas y resultan más evidentes y más inmediatamente aprovechables." (Williams: 1980: 156). 
actos de habla de Austin - como "profundamente performativos: los afectos son en sí mismos actos capaces, por ejemplo, de alterar la esfera pública con su irrupción" (2013: 11). Y agrega, en línea con la postura de Peluffo, "la lógica de los afectos cuestionadora de los dualismos y sustancialmente performativa-implica sostener elementos clave del posestructuralismo, tales como la impugnación de la estabilidad de las identidades, la disolución de los binarismos y una actitud deconstructiva" (2013: 13). El enfoque en los sentimientos que propone Ahmed y rescata Macón está -como explica Leonor Arfuch - lejos de la mirada de las neurociencias y en línea con una lectura (heredera de las ideas de sociólogos como Durkheim y Elias) que imbrica emociones a lenguaje, entorno social e ideología. Así vistas, las emociones, "esenciales para el aparato psíquico y social, ligadas a objetos no siempre conscientes, son inseparables de las sensaciones corporales y suponen tanto ligazón como movimiento, un aspecto importante en términos de estructura social" (Arfuch, 2015: 252). En este sentido, analizar fenómenos culturales (obras artísticas, cartas u otros) atendiendo al papel de las emociones permite a veces una "resignificación de la acción colectiva" (Macón, 2013: 11) presente en ellos. Si entendemos, siguiendo a Prochasson (1993), que el orden del discurso de cada autor está supeditado a la dimensión colectiva del intelectual - pensada a partir de la tríada que forman sus lugares de encuentro y actividad (lieux), sus medios de expresión y comunicación (milieux) y la compleja red de relaciones (reseaux) que teje a su alrededor-, la lectura de textos desde lo afectivo implica intentar acercarse, no ya a cada voz en tanto expresión de una individualidad, sino al sentir de una época.

Por su parte, la historiadora inglesa Barbara Rosenwein propone que, a lo largo de la historia y según cada cultura, la sociabilidad se organiza en grupos humanos que se rigen por códigos afectivos específicos. Dentro de cada grupo, determinados sentimientos son valorados y otros reprimidos. Los sujetos que circulan por esos espacios conforman una misma "comunidad emocional" y se distinguen entre sí por el modo en que acatan, transgreden y codifican esos estados emocionales normativos (Rosenwein, 2006: 11). Así, dentro de determinado grupo se valoran ciertas emociones, se ignoran o reprueban otras. Se generan un control y un estímulo recíprocos respecto del compromiso de cada miembro para con dicha normativa. ${ }^{11}$ Las emociones son, ante todo, instrumentos de socialización: están culturalmente construidas, se retroalimentan y sostienen el sistema cultural que les dio origen, y condicionan los vínculos humanos, desde los más privados hasta los más públicos o institucionalizados - ver también Armon-Jones (1986) y Scheff (1997).

Desde una perspectiva emparentada con la del giro afectivo, la de redes intelectuales, Claudio Maíz ha estudiado el funcionamiento dinámico de este grupo de intelectuales románticos antirrosistas a partir de sus publicaciones periódicas. Lo que propone en torno a las "redvistas" también se aplica a las cartas: se trata de textos que contribuyeron a la creación de una red que permitió "superar, gracias a una geografía imaginaria (o virtual, podríamos agregar) las limitaciones del medio en el que nace" (Maíz, 2014: 82). Las redes en general lo son en tanto y en cuanto sea posible la identificación de un objetivo común, un lenguaje más o menos homogéneo y las políticas de amistad que animan las relaciones, la dinámica de sus vinculaciones" (Maíz, 2014: 76). A través de estas redes, muchas veces es posible dilucidar las densidades de los movimientos estéticos y, en este sentido, interesan más "las relaciones (contactos, correspondencia, amistades), es decir la trama, que el contenido de las ideas estéticas,

11 "Emotional communities are largely the same as social communities -families, neighborhoods, syndicates, academic institutions, monasteries, factories, platoons, princely courts. But the researcher looking at them seeks above all to uncover systems of feeling, to establish what these communities (and the individuals within them) define and assess as valuable or harmful to them (for it is about such things that people express emotions); the emotions that they value, devalue, or ignore; the nature of the affective bonds between people that they recognize; and the modes of emotional expression that they expect; encourage, tolerate, and deplore." (Rosenwein, 2006: 11) 
ya largamente estudiadas" (Maíz, 2014: 76). En coautoría con Fernández Bravo, Maíz propone pensar nuevos modos de religación para la literatura: "el estallido de las unidades de lectura vigentes en numerosos fragmentos dispersos, que pueden imaginarse y ser recompuestos para leerlos con la ayuda del concepto de red" (Maíz y Fernández Bravo, 2009: 12). La red es pensada en dos niveles: como herramienta heurística para leer la dispersión cultural (que emerge hoy, pero que en rigor puede reconocerse en diversas coyunturas y está presente en la historia de América Latina desde la conquista) y como objeto de análisis, que conecta una constelación de textos y posiciones de sujeto separadas entre sín (Maíz yFernández Bravo, 2009: 12).

\section{Sentimientos prestigiados}

Alrededor de la década de 1860, la cultura rioplatense ingresa en lo que el historiador uruguayo Pedro Barrán denominó "la era del disciplinamiento" (1989): un paulatino endurecimiento de las normas, una nueva estructura de sentimientos más prescriptiva y represora que la anterior, más "moderna", en términos de Norbert Elias. ${ }^{12}$ Las cartas que aquí nos ocupan son anteriores a este proceso de represión, autocontrol, ahorro y constricción de lo emocional. En pleno auge del romanticismo revolucionario, la expresión del amor entre hombres, la sensibilidad y la fragilidad emocional no se piensan como detrimentos de lo masculino sino como rasgos propios del ser civilizado, refinado y culto, opuesto a la brutalidad federal. Según Marcela Ternavasio, la escritura de cartas fue durante el rosismo un medio de ejercer el poder "a través de la personalización del mando y la obediencia" (Ternavasio, 2005: 15). La escritura epistolar era una actividad a la que Rosas dedicaba varias horas del día y conformaba una parte central de su construcción y sostenimiento del poder. Lejos de este artículo el ambicioso objetivo de cotejar cartas unitarias y cartas federales: diremos simplemente que el tono autoritario y exhortativo a veces presente en cartas federales -según ha analizado Magdalena Arnoux (2016: 197-220) - parece contrastar con las recurrentes menciones afectuosas que leemos en las cartas que se intercambian los jóvenes del Salón Literario. El amor entre hombres, la amistad y el deseo de abrazarse van puntuando, como estribillos, estas cartas de unitarios exiliados. "Mi amigo", le escribe el joven Gutiérrez al apenas cuatro años mayor Echeverría: "acabo de leer la carta q. V. dirige a Thompson y he bendecido a la Providencia que me deparó tales amigos". Y se explaya así en su admiración:

Yo lo esperaba todo de V., Echeverría, porque le conozco y con la sinceridad de amigo le digo que en su carta hai algo de sublime. V. ha mostrado que el poeta es sacerdote y que perdona las flaquezas del corazón.

Tras esta temprana e inquebrantable idolatría al amigo, Gutiérrez se despide con un ruego:

Amémonos y enseñemos al mundo que solo crecen las virtudes a la sombra de los sentimientos elevados y generosos, etc., etc. Adiós, mi Estevan, va a parecerme un siglo el tiempo que tarde en abrazarle. (T. I: 183)

Por su parte, Florencio Varela, recién emigrado de Buenos Aires en su temprano exilio a Montevideo, no vacila en escribirle a Gutiérrez que extraña "el placer de abrazar a V. y hacerle compañía”: “¿Sabe V. amigo que extraño muchísimo la [compañía] de V.? 12 En The Civilizing Process, Elias estudia los cambios subjetivos que se produjeron con el advenimiento de la Modernidad. Propone, entre otras cosas, que la formación de los Estados-nación supuso la inhibición ("restraints") de las emociones y la gestación del autocontrol: la internalización de ciertas pautas de autocensura y de freno de las pasiones y emociones, como resultado de la red de interdependencias económicas y sociales que resulta de la industrialización y los procesos de modernización. 
Estaba tan habituado a ella que no me acomodo con su falta". Y, antes de despedirse, le ruega: "No se aburra V. de mis cartas, quiérame como le quiero yo" (T. I: 157). Corre el año 1833 y, en otra carta, el publicista escribe, nostálgico: "debe V. creer que toda mi vida recordaré como una fortuna la circunstancia que me proporcionó el gusto de ligarme con V." (T. I: 159); "Quiérame como le quiere su Flor", se despide (T. I: 184); "vea V. a Thompson y abrácele V. por mí. Quiero muchísimo a Manuel Eguía, dígaselo V. por mí" (T. 1: 207); le pide en otra carta. "Con toda mi alma, amigo queridísimo, doi a $\mathrm{V}$ el abrazo que me pide en su carta del 6" (T. I: 234); "[d]isponga del tierno afecto de su apasionado amigo y servidor" (T. I: 215), escribe Vicente López a Gutiérrez (en una carta sin año pero que los editores del Epistolario presumen de 1841). "No vivo sino para desear que nos hallemos en algún lugar del mundo juntos, acompañados de aquellos amigos de nuestra predilección entre los cuales la vida es tan agradable" (T. I; 287), le escribe Gutiérrez a su "Estevita" el 21 de noviembre de 1844. Desde el exilio, las cartas son prueba de cariño y garantía de sostén de la amistad. A veces van acompañadas de poesías o de manuscritos de libros de algún miembro del grupo (como es el caso de Varela al recibir Los consuelos de Echeverría remitido en carta de Gutiérrez): "Me propongo escribir a V. despacio una, dos o más cartas sobre esta colección de poesías, cartas que dirigiré a $\mathrm{V}$. y a nuestro Thompson de mancomun et in solidum, porque le quiero mucho, como a V." (T. I: 181). "A estos mismos no los estimo en mucho", leemos en carta de Gutiérrez a Alberdi en referencia a unos versos que le envía, "y no los habría copiado en limpio si no fuesen la única cosa que tengo que ofrecer a mi querido amigo en prueba del amor y de la estimación que le profeso" (T. I; 297, carta del 20 de mayo de 1845). Escritura de minucias cotidianas, envío de textos literarios como regalos y frases amorosas como pruebas de afecto se tornan un mismo gesto en estas epístolas y resultan con frecuencia un refugio a la desazón del exilio y/o a la alta conflictividad del entorno: "He recibido los ejemplares de sus obras últimas y solo he visto letra de V. en la dirección que de ellas pone a mi nombre", le escribe Gutiérrez a Echeverría en 1846 desde Valparaíso, “[e]s V. un valiente que en medio de tanta desazón y de tanto silbar de balas se ocupa de cosas tan serias y conserva vivas su fe y su palabra de apóstol." (T. II: 76). ${ }^{13}$

Al parecer, a más tiempo en el exilio, mayor efusividad y mayor marca personal en los saludos que, aunque tienen siempre algo de retórico, no podrían explicarse tan solo apelando a la convención. " ${ }^{14}$ "Mi amadísimo amigo", le escribe Félix Frías a Gutiérrez el 14 de agosto de 1850, "Ya ve por el adjetivo que le quiero como siempre y tal vez más que antes, pues se aprecia más el mérito de los amigos cuando están ausentes" (T. II: 112). Y termina su carta de un modo hoy tal vez enigmático (pues no contamos con el contexto de producción): "Perdón, no tengo querida francesa, es preciso que lo acaricie. Mi cama lo espera" (T. II: 112).

Menos inusual que la expresión homoerótica es en estas cartas la jactancia machista de las aventuras heterosexuales: "El calor excesivo y algunas distracciones amorosas hacen que me contraiga menos al estudio que en la estación anterior" (T. II: 36), le escribe en otra carta también Félix Frías a Juan María. Más elíptico que Frías, Alberdi le cuenta al amigo:

Todas las noches de los tristes días tengo la compañía de un ángel que me sonríe, 13 Sobre este constante "silbar de balas", escribe Myers: "no es desdeñable el hecho de que, entre 1829 y 1848 nunca dejó de oírse el ruido de las armas en al menos una porción del territorio argentino. Y junto con la guerra interna, aquella entablada con potencias extranjeras también constituyó un elemento perdurable en el gobierno rosista" (Myers, 2011: 21). Aunque narrador y narratario se encontraban fuera del país al momento de la carta, el clima de lucha facciosa y terror que describe Myers les cabe también a sus nuevas residencias.

14 Roger Chartier analiza lo altamente pautado que ha estado durante el siglo XIX el género epistolar en Francia (pero su estudio es extensible a otros puntos geográficos). La proliferación de los manuales de escritura epistolar —compendios que reglaban las pautas del género- Ilamados "Modèles" ("Secretarios”), es una prueba de esta alta codificación discursiva (Chartier, 1993: 308). 
que me mira, que me dice mentiras ilusorias, y con esto me reconcilio con Chile, país de tristes días y dulces noches. (T. II: 33)

"Paso mi buena vida, mi querido D. Esteban", escribe con arrogancia desde Valparaíso Gutiérrez, "las mujeres aquí son mansas como agua estancada" (T. II: 16). También de tono jactancioso es la referencia de Mármol a Juan Carlos Gómez, que hace de portador de una de sus cartas: "va enojado con la especie humana, de mal humor, excéntrico", le advierte el autor de los Cantos del Peregrino al destinatario de la misiva, Gutiérrez, "pero le diré al oído que todo esto es de día, porque de noche es un putañe...), nada, no he dicho nada" (T. II: 11). Es este mismo Juan Carlos quien le solicita, en carta también dirigida a Juan María: "No deje de traerme o de escribirme algunas de aquellas anecdotillas que se deslizan en nuestras conversaciones y sus recuerdos del bello sexo, que tanto quiero y que tanto le ocupaban a V." (T. I: 264). Pero quizás la más explícita referencia sexual del Epistolario sea la confesión de Sarmiento (dirigida a un destinario colectivo: "Juan María Gutiérrez, Miguel Piñero, Demetrio Peña y demás amigos de Valparaíso"):

La señora Mendeville, por unas palabras de Gutiérrez, me izo procurar, nos izimos amigos, pero tanto qe, una mañana solos, sentados en un sofá, ablando ella, mintiendo, ponderando con la gracia que sabe hacerlo, sentí... Vamos, a cualquiera le puede suceder otro tanto, me sorprendí víctima triste de una erección, tan porfiada que estaba a punto de interrumpirla i, no obstante sus sesenta años, violarla. Felizmente, entró alguien i me salvó de tamaño atentado. (T. II: 37)

En las antípodas del desenfado sarmientino, el católico y constreñido Luis Domínguez se esmera por "encarrilar" a sus amigos por la senda normativa. En una carta que le dirige a Gutiérrez el 7 de junio de 1844, leemos una de sus defensas del matrimonio:

Ya que V. se confiesa parrandero todavía, permítale a un amigo, a un hombre casado qe le diga qe eso no es bueno; qe es preciso qe piense en mejorar de suerte a todo trance, aunque sea condenándose por algún tiempo a mayores privaciones de las que se sufren por el hecho de vivir en ese rincón del mundo [...]. Estoi persuadido [...] de las ventajas que gozan los hombres casados en las sociedades civilizadas. ¿Ni cómo sería de otro modo, una vez qe el matrimonio y la familia es la base de toda civilización? El hombre qe muere soltero muere incompleto. Todo en la Creación ha nacido p. dejar una posteridad y perecer. (T. I: 276)

Con "ese rincón del mundo", Domínguez se refiere a Rio Grande do Sul, uno de los destinos más padecidos por Gutiérrez (aunque no más que la desolada Pelotas). ${ }^{15}$ Y la mención no es arbitraria: aunque no contamos con la carta de Juan María a la cual Domínguez está respondiendo, es fácil conjeturar que habría habido en ella al menos una queja sobre la vida de proscripto, pues el dolor del exilio es, junto con el amor a los amigos, el envío de poemas como regalos y las anécdotas de aventuras heterosexuales, otro de los afectos culturalmente prestigiosos y recurrentes en este corpus.

15 "Le creo ya en Pelotas pero no empelotado", le escribe Echeverría desde Montevideo a Gutiérrez (en su carta del 21 de marzo de 1844), poniendo una cuota de humor al relato desolado que le ha hecho el amigo el mes anterior sobre aquel lugar. "Esa ciudad no tiene nada de agradable, está atrasada, hai arena en las calles hasta el tobillo y el calor es insoportable" (T. I: 262)". Luis Domínguez, por su parte, lo alienta de este modo: "mucho deseo que esté V. ya más avenido con Rio Grande y sus arenales, con su abundancia de porquería y escasez de mujeres y con todas las demás seductoras circunstancias que me refiere en su mui estimada del 26 de febrero". (T. I: 266) 


\section{El dolor del exilio}

"Me parece que me aguarda una vida vejetativa y de puro destierro", le escribe Gutiérrez a Echeverría en 1844 (T. I: 262). "La poca estabilidad de mi vida me ha privado dedicarme a nada, he perdido miserablemente un año, algunas veces he querido idealizar algo y me invaden mis cosas individuales imposibilitándome para todo pensamiento general", le confiesa Carlos Gómez a Gutiérrez, también en 1844, y cierra su carta con tono nostálgico: “¿Cuándo volveremos, Juan María, a ocuparnos de alguna cosa interesante y agradable, como cuando veíamos lejos la contienda? ¿Cuándo volveré yo a aplaudirlo en otro certamen?" (T. I: 264). Mármol, por su parte, tras narrar los infortunios del exilio y las dificultades logísticas de los traslados, concluye con un esforzado gesto de optimismo que no logra ocultar su melancolía: "es necesario no postrarse ante la desgracia en esa senda de infortunios que recorremos desde niños; es necesario ponerse en movimiento para ahogar en el trabajo el recuerdo amargo de nuestras pasadas esperanzas" (T. I: 266). Gutiérrez vive su exilio en Brasil con abulia y gran nostalgia por su hermano: "Tengo ansias de vivir con Juan Antonio, es lo único que me haría llevadera la ausencia del Río de la Plata y también la única perspectiva de mejor fortuna. Por aquí no hay nada que hacer de provecho" (T. I: 282), le escribe a Echeverría el 7 de agosto de 1844. "He olvidado hasta el leer de corrido y las Musas me han huido como canes que se ahuyentan de casa del amo por falta de migas. Perdone V. la comparación; estoy embrutecido" (T. I: 282), le confiesa hacia el final de su carta.

"Lo peor es que el clima de este lugar (hablo de Valparaíso) no es bueno para mi temperamento" (T. II: 59), le escribe Gutiérrez a Echeverría. "Me siento aflojar [...]. Estoy harto de estas cosas, pero hambriento de patria [...] guárdese, mi amigo, y pidamos a Dios que permita vernos todavía en este mundo, ¡qué buen día será ese para mí!" (T. II: 59). "Yo lo paso aquí como en el limbo, sin pena ni gloria", reflexiona en otra carta Gutiérrez, "[m]i vida corre entre un paréntesis (T. II: 42).

La sensación de vivir en tránsito, en un mientras-tanto, la desazón ante la pérdida de lo que se ha dejado atrás y la esperanza de un futuro diferente, reaparecen en otra carta, también de Gutiérrez a Echeverría: "No vivo sino para desear que nos hallemos en algún lugar del mundo juntos, acompañados de aquellos amigos de nuestra predilección entre los cuales la vida es tan agradable" (T. I: 287). Sueña -todos ellos sueñan y lo escriben - con un futuro compartido y en la patria: "no pienso, mi amigo, vender el terreno de La Teja", le cuenta a Estevita en su carta del 7 de agosto de 1844 (T. I: 282), "tengo la esperanza de edificarlo cuando sea viejo, para tomar campo en el verano; allí hablaremos de nuestras fechorías, con el habla temblona y el bordón en la diestra. Dese por convidado. Más seguro es que el rendez vous se verifique en el valle de Josafat. Esperemos" (T. I: 282). En otra carta, también a Echeverría, con menos proyección a futuro pero igual grado de nostalgia, escribe Gutiérrez: "Estamos contentos con la esperanza de abrazarle pronto, aunque no sea más que para ayudarnos a sentir nuestros males y nuestra pésima situación" (T. I: 218). En otra carta, dirigida también al "apóstol", leemos: "Aquí estamos trabajando como unos changadores; nos sostiene la esperanza de volver a la patria; esta idea nos alijera el trabajo y nos da aliento para la tarea más penosa de la vida: esperar, esperemos pues." (T. II: 39)

Expresado como angustia o como incertidumbre por la situación política del Río de la Plata, a través del relato de las dificultades de adaptación a los nuevos lugares (variados porque cada emigrado, a su vez, va probando suerte en diversos puntos de América, y a veces también de Europa), como melancolía o bien como sensación de estar "a la espera" de otra cosa, el dolor del exilio es un sentimiento que escande y se reitera, románticamente prestigioso, a lo largo de todas estas cartas. 


\section{El reparto de roles}

Como dijimos, uno de los aspectos constitutivos de toda comunidad emocional es, según Rosenwein, el control recíproco de las conductas de cada uno de sus miembros. ${ }^{16}$ En estas cartas se percibe, por momentos, cierta exigencia o pedido de rendición de cuentas de lo que cada uno ha hecho en pos de la fundación de una cultura propia, una lengua, una historia o una poesía diferentes de las españolas. Cada integrante debe ubicarse como poeta (según la concepción romántica: un profeta, portavoz de una verdad) o como investigador de fuentes históricas (una suerte de fundador de la independencia cultural) y/o como difusor/crítico/antologador de las obras de la patria (o de América, en este caso).

Desde los primeros años de su exilio hasta su retorno, se ve un gradual posicionamiento de Gutiérrez como crítico y difusor de las obras de los amigos (sobre todo, de los textos de quien más admira: "Estevita") y la simultánea ubicación de Echeverría como el gran poeta visionario, "el apóstol". Gutiérrez se adjudica para sí, también, el mandato generacional de la investigación histórica: como dijimos, de todos ellos, es él quien más antepone el proyecto grupal a la obra personal. La creación de la antología América Poética (que se registra a lo largo de sesenta cartas en estos tomos) es un ejemplo de hasta qué punto Gutiérrez dedicaba sus mayores esfuerzos y su escritura a difundir las obras ajenas. A esto se suma la cantidad de solicitudes - a veces, exigencias-que recibe de sus amigos en torno a sus respectivos libros. Echeverría, Mármol, Sarmiento le reclaman todo el tiempo que reparta, venda, difunda y reseñe El ángel caído y el Dogma socialista, los Cantos del Peregrino, el Facundo, respectivamente. Sarmiento es quien se muestra más obsesionado por hacer llegar el Facundo a la mayor cantidad posible de lectores, por recabar reseñas y buenos comentarios sobre "su Odisea".

Así como Varela junta información sobre la época rivadaviana, y el uruguayo Teodoro Vilardebó sobre la colonización española en el Río de la Plata, Gutiérrez -además de trabajar sobre obras de los amigos- recopila fuentes sobre las culturas precolombinas. En las páginas que siguen indago estos "pactos" del afecto y los posicionamientos de cada miembro dentro de la comunidad emocional en estas cartas.

En la comunicación entre Gutiérrez y Echeverría - signada por una fuerte admiración del primero hacia el segundo- esta suerte de control o exigencia afectiva está casi siempre referida al reclamo de escritura. El Epistolario reúne veintinueve cartas (ocho escritas por Echeverría y veintiuna por Gutiérrez) intercambiadas entre ambos amigos entre 1834 y 1847. En las ocho de Echeverría puede percibirse el lugar de liderazgo del poeta frente a su amigo crítico, su autoridad dentro del grupo y su convencimiento de tener una "misión" para con la patria: el deber de ilustrar y abrirle los ojos al ignorante "pueblo", la certidumbre respecto de la fuerte ligazón entre su proyecto político y su proyecto literario (es decir, su escritura como herramienta eficaz para dar cuenta de nuestra cultura). En una carta del 21 de enero de 1837, el joven poeta romántico ya se presenta ante Gutiérrez como quien prescribe (y encarna) el deber ser de la poesía:

Para que pueda llenar dignamente su visión profética, para que pueda obrar sobre las masas y ser un poderoso elemento social, y no como hasta aquí entre nosotros y nuestros padres, un pasatiempo fútil y cuando mas agradable, es preciso que la poesía sea grande y bella y sublime y se manifieste bajo sus formas colosales. (T. I: 196)

16 Otro rasgo de cohesión afectiva —además del mutuo control— sería, según plantea Ahmed (2004), la identificación de determinados identidades y cuerpos que, a partir de portar ciertos rasgos, pasan a ser percibidos como enemigos de esa comunidad. En el caso de los románticos de 1837, está claro que este enemigo común es Rosas. En este sentido, no sorprende encontrar numerosas referencias demonizadoras tanto hacia "el tirano" como hacia Pedro De Angelis, su principal publicista. No me detendré en ello porque es uno de los aspectos más trabajados ya en torno a este grupo de intelectuales. 
Aún muy joven, el autor de Los consuelos atribuye todos esos méritos a sus propios poemas, algunos de los cuales envía adjuntos a esa carta de 1837. Desde el inicio de esta correspondencia se ve que, en la mayoría de sus cartas, Echeverría envía sus poemas para que Gutiérrez los lea y los comente, o bien le manda un lote de libros para que el amigo los venda y le haga llegar el dinero. Convencido de la genialidad del amigo, unos años más tarde, en carta del 7 de agosto de 1844, Gutiérrez le sugiere: "V., que está en vena, debería trabajar una monografía histórica sobre las letras argentinas, que en Montevideo no le faltarán materiales. Haga de modo que cuando nos encontremos pueda mostrarme muchas cosas nuevas y buenas" (T. I: 283). La voz poética de Echeverría se impone dentro del grupo de proscriptos. Gutiérrez es acaso el principal constructor de este lugar para el amigo "Estevita": "Hoi le escribo con el objeto especialísimo de alentarlo a que pulse la lira", leemos en la carta del 8 de mayo de 1841:

Se abre un certamen poético, como vera Vd. por los diarios, para cantar el día de Mayo. Creo que es su deber de todo el que sepa hacer versos el concurrir con los suyos esta vez. Vd. debe cantar, aunque no tenga más tiempo que el de una noche. [...] todos los que trabajan son pigmeos al lado de Vd., que tiene la voz alta cuando piensa y habla en la lengua de los inmortales (T. I: 219)

Con el correr del tiempo, el posicionamiento de Echeverría como el portador de una verdad reveladora y guía intelectual de un pueblo ciego se ratifica: "Si no se dice la verdad la literatura no puede adelantar porque el pueblo no tiene criterio propio y ni las obras ni los talentos jamás serán apreciados debidamente", le escribe a su leal admirador y futuro biógrafo. Reflexiona sin modestia: "Soy de la opinión de que se debe hablar sin embozo y alto cuando se trata de progreso literario y político, y estoy resuelto a hacerlo sufra el que sufra. De otro modo no se anda, se retrocede o se está inmóvil". Luego, la indicación a Gutiérrez: "Haga V. y todos los amigos en Chile lo mismo porque marchemos unidos en espíritu y en tendencias" (T. I: 291).

En esta línea de admirado/admirador, Echeverría no afloja en su envío de poemas para que el amigo admire. El 21 de marzo de 1844, le escribe: “¿Creerá Vd. que todavía no he podido reunirme con la primera parte del Ángel caído para enviársela? Concluyo la segunda y más difícil de las 4 en que pienso desarrollar el asunto. Me parece será una cosa nueva con la pintura de un baile nuestro con todas sus hablillas y peculiaridades" (T. I: 265). Al mes siguiente, le cuenta: "He concluido la segunda parte del Ángel caído. Tendrá como 1.500 versos. Mis ideas, trabajando, se han entendido tanto que creo que el poema será indefinido como el Don Juan de Byron" (T. I: 267). La frase evoca la crítica al exceso de "amor propio" de Echeverría que le hiciera Florencio Varela, ${ }^{17}$ pero lo que interesa es que en ella puede verse la concepción de la poesía como programa cultural y civilizatorio: "En la segunda parte he entrado de lleno en el fondo de nuestra sociabilidad y todo el poema no saldrá de ella. Representa o bosqueja un gran baile nuestro, ${ }^{18}$ en el cual aparecen a bulto las principales figuras del poema" (T. I: 267). Esta idea de la poesía como herramienta civilizatoria es compartida por todo el grupo. Veamos un ejemplo en carta de Gutiérrez a Echeverría: "Agradezco los versos porque sabe $\mathrm{V}$. cuanto amo la poesía y particularmente la de mis nobles amigos que trabajan por la libertad de la patria y la civilización" (T. I: 281). La misión civilizatoria otorgada a la poesía va acompañada de una concepción del poeta como héroe y como genio iluminado (ideas propias del Romanticismo). "He recibido los

17 En carta del 16 de diciembre de 1834, cuando aún los jóvenes del Salón Literario están en Buenos Aires, desde su temprano exilio escribe Varela a su íntimo amigo Gutiérrez: "Siento en el alma que tenga aquel joven tanto amor propio y que se haya abajado a personalizar una cuestión que era puramente literaria y de amigos. Es un defecto ese capaz de deslustrar en parte su mérito" (T. I: 182). Siempre defensor del clasicismo, Varela no vivencia la literatura como sí lo hacen sus contemporáneos románticos: como algo indisociable de lo político y de lo afectivo.

18 Itálica del original. 
ejemplares de sus obras últimas", le avisa Gutiérrez en carta del 4 de diciembre de 1846, "[e]s V. un valiente que en medio de tanta desazón y de tanto silbar de balas se ocupa de cosas tan serias y conserva vivas su fe y su palabra de apóstol." (T. II: 76).

Desde jóvenes, con las cartas y a la distancia, Echeverría y Gutiérrez construyen recíprocamente sus posicionamientos diferenciales dentro del grupo. ${ }^{19}$ En síntesis, ambos coinciden desde la década del 30 en ubicar a "Estevita" en el lugar del poeta mayor de esa generación y a Juan María como antólogo y estudioso de su obra y, sin escatimar pretensiones, de la literatura argentina y americana. Como propone Iglesia en referencia a Echeverría, "cada etapa de su breve vida literaria (mucho más breve aún que su ya breve vida adulta) fue construida a partir del énfasis crítico de sus contemporáneos y, en especial, del voluntarismo crítico de Juan María Gutiérrez" (Iglesia, 2014: 353).

El lugar de Gutiérrez dista de ser altruista: si, por un lado, implica dedicar generosamente su trabajo letrado a dar visibilidad a sus amigos poetas, también supone cierto poder sobre ellos. En las cartas se puede ver cómo se va tornando un evaluador o juez de los deberes de esa comunidad emocional (dentro de los cuales también están los propios deberes). En carta del 30 de enero de 1845, le informa al amigo "Estevita" sobre la tarea de cada miembro del grupo:

He leído un opúsculo de Frías sobre materias religiosas, y otro de Alberdi: Política continental. Mármol trabaja en un poema titulado El Peregrino, en el cual lucen las cualidades que siempre mostró, depuradas de sus defectos de inexperiencia. Entre los nuevos elementos que deben entrar en la literatura del Plata empiezan a aparecer las escenas del Océano, al seno del cual ha echado la Revolución a algunos de nuestros versificadores. Todo será en nuestra gloria, gracias a nuestro magnífico y doloroso destino actual. Courage, mon ami!, trabaje y trabaje con empeño. (T. I: 292)

Además del control de Gutiérrez en torno de la tarea/contribución de cada uno, esta cita permite ver, a través de la referencia a "nuestro doloroso destino actual", la semantización del exilio como el precio que han de pagar para el nacimiento de una literatura propia, que nombre y dé cuenta del paisaje en el cual los guerreros de la Independencia lucharon físicamente. Asimismo, la explicitación del recíproco estímulo controlador: "trabaje y trabaje con empeño", le indica a Echeverría el compromiso con el estudio, sobre todo, con la producción escrita como modo de dar batalla política contra Rosas. También incluye, por supuesto, su propio deber de crítico: "Yo me propongo publicar donde pueda mis estudios continuos sobre nuestra literatura; los poetas de mi patria, así como los guerreros de la Independencia, son mis héroes, mis amores, mis lares, y he de hacer cuanto pueda por su gloria. Mi crítica no es la de usted; yo no pongo de vulto sino lo bueno" (T. I: 292). Gutiérrez se coloca en un lugar de autoridad como crítico literario más juicioso y exigente que el amigo: "Mi crítica no es la de usted; yo no pongo de vulto [sic] sino lo bueno!" (T. I: 292). Como parte de este rol de nodo central del grupo, conector principal en su función de crítico y difusor de las obras de otros e indisociable del afecto y del dolor del exilio, Gutiérrez le cuenta a Echeverría la ubicación de cada amigo en Valparaíso:

Alberdi está bueno, acreditado como abogado y considerado por todo el mundo. Juan Carlos Gómez, que siempre ha sido un joven a quien he querido mucho, está de redactor del Mercurio y trabaja en el escritorio de Gallardo; paso con él muy buenos momentos. Por lo demás, querido, este es un agujero, incómodo, ruidoso y embarrado. (T. II: 59).

19 “En períodos de construcción (como lo fueron, indudablemente, el de la formación de la nación durante la primera mitad del siglo XIX y el de la organización del Estado hacia 1880), la crítica -al tiempo que analiza - señala las necesidades estéticas como una misión patriótica" (Amante, 2010: 162). 
Y agrega, solícito y afectuoso: "Dígame qué puedo hacer por V., por sus proyectos. Aunque pobre, tengo un corazón rico en afectos para mis amigos y este caudal suele producir frutos que no son de desechar" (T. II: 39-40). Dar visibilidad a los proyectos del amigo es, como forma del afecto, el rol que Gutiérrez se ha asignado dentro del grupo.

\section{En nombre del afecto}

Lo afectivo también aparece en estas cartas como prerrogativa de gestiones: es a veces apelando al cariño que los integrantes de esta red se piden favores o se exigen privilegios (casi siempre relativos al envío o distribución de libros). A fines de 1846, Mármol le manda desde Montevideo a Gutiérrez, en el buque Gassendi, "20 ejemplares más" de los Cantos del Peregrino y le indica: "si, como creo, los libros no pueden venderse todos en Chile, vea de mandarlos a Bolivia o al Perú pero, por supuesto, por conductos seguros" (T. II: 78). En el párrafo siguiente, como disculpándose de tanto pedido, reflexiona: "Hay algo de brusco en la manera de empezar esta carta, y sobre todo, algo de atrevimiento en endosarle encomiendas de esta especie y con tan pocos preámbulos, ¿no es verdad, mi querido Gutiérrez? Pero he aquí que esta palabra querido salva todo: porque te quiero te pego" (T. II: 78). Luego de la explicitación del afecto como "llave" que legitima los pedidos, Mármol menciona otro tema recurrente en estas cartas - y que aquí hemos dejado de lado-: la estrecha relación entre el dinero y la literatura:

V. será tan bueno que me reducirá a patacones todo lo que le mando, ¿no es verdad? Y V. me los mandará en el primer buque que venga, ¿no es verdad? Y V. no me cobrará la comisión ni permitirá que el librero se la cobre, ¿no es verdad? $\mathrm{Y}$ a bien que si no hace $\mathrm{V}$. todo eso lo pongo de vuelta y media en una obra que debo publicar el mes que viene. (T. II: 78)

Sin el humor habitual de Mármol, Sarmiento - al enviarle a Gutiérrez su Facundo recién publicado- escribe: “¿Quiere V. encargarse de analizarlo por El Mercurio, y decir que es un librote estupendo, magnífico, celebérrimo? Sin miedo de ofenderme diga en este sentido lo que le dé la gana, soy tolerantísimo" (T. II: 5). Esta primera mención del Facundo inaugura una serie de exigencias de difusión de la obra que Sarmiento sostendrá para con Gutiérrez a lo largo de varias comunicaciones, con un tono de crecientes reclamos e ironía, no alejados del afecto pero tampoco del menosprecio. "¿Cómo le va a V.? ¿Qué hace? ¿Por qué se hace la niña bonita y no me escribe?", lo increpa en carta del 24 de julio de 1845. "Vea: esté a la mira de la salida del buqe para Europa para qe endilguemos el Facundo por alla, i para Montevideo también" (T. II: 6). Sarmiento no escatima en sus menciones de la amistad y el afecto como justificativos a sus reclamos en torno al Facundo. En nombre del cariño, pide con creciente insistencia reseñas y gestiones para su obra. A este gesto pedigüeño, se yuxtapone un latente desprecio por el modo de vida de Gutiérrez, que pasa sus mañanas como docente y sus tardes escribiendo cartas. " VVaya qe es curioso ver a un pobre gaucho de la Pampa, tant soit (-peu-) poeta ensañado a marinar por estas Méricas!", le escribe burlándose de su labor de director de una escuela naval, "me lo imagino a $\mathrm{V}$ con su couvée, como la gallina qe cría patitos y los ve con orror i asombro lanzarse a la agua. 'No, ijitos, os vais a aogar!"” (T. II: 8). Y, apelando a la empatía del verbo en plural, continúa con su tono sarcástico y, a la vez, afectuoso:

Pero V. no sabe de todo lo qe somos capaces los arjentinos, sobre todo si estamos emigrados i falta qé comer. Entonces nos sentimos titanes, entonces nos revelamos a nosotros mismos. Yo, provinciano, viñatero, si algo e sido en mi vida, flanneur 
mas propiamente ablando, me enderezo, diarista, politico, istoriador, Director de Escuelas Normales, qé sé yo qé. ( $T$. II; 9)

Sobre el hábito de Juan María de recluirse para escribir, tanto cartas como investigaciones y antologías, Sarmiento también se burla: “¿Cómo le va a V. en su ermita, ambiente fresco y embalsamado, arbustillos verdes y florescentes? ¿No tiene jilgueros y canarios? Es lástima qe no se aga regalar el oido con sus cantares! Pero arpas eólicas pueden suplirlos" (T. II: 8). A juzgar por cómo se inicia la siguiente carta de Sarmiento, podemos inferir que Gutiérrez ha reaccionado a la ironía sanjuanina con un prolongado silencio. Hay una creciente tensión entre la prepotencia de Sarmiento y su uso de la retórica del afecto. El sanjuanino no vacila en apelar al cariño para aumentar sus exigencias de prensa del Facundo:"Es V. un taimadísimo amigo a quien es preciso importunar sin descanso para arrancar una palabra" (T. II: 8), le escribe enojado o sarcástico. "Vamos, déjese querer":

Le remito un cajón qe le entregará a Peña, el cual contiene 170 ejemplares de mi Odisea, como se a complacido en llamarla V. por una admirable mezcla de afecto, convencimiento i inofensiva ironía. [...] Estos 170 los remitirá a Montevideo a alguno de sus amigos para qe, asignandoles un precio vendible los aga circular donde convenga. Van tres en pasta para Varela, Echeverría, Rivera Indarte, los únicos tres nombres de por alla qe me suenan al oido bien claros y distintos. (T. II: 8)

No conforme con estas órdenes, Sarmiento agrega:

Pero volvamos a su misión de derramar la Odisea por toda la redondez del orbe. ¿A qé no a mandado un ejemplar al Times? ¿A q no a escrito una palabra a sus amigos de Francia al National, la Democracia Pacífica, Revista de París y de Dos Mundos, etc, etc? Vamos, ágalo [...] para acerme saltar de contento, para acer aspirar a un pobre amigo un poco de la fragancia de las lisonjas qe mecen el amor propio. (T. II: 9)

Las exigencias van subiendo de tono, siempre en nombre del afecto y la amistad: "Lo ago a V. responsable con su vida i empleo del exacto desempeño de esta comision, prometiéndole ascenderlo al mas complaciente y oficioso amigo de lo qe le doi desde aora el grado" (T. II: 9), le escribe el "amigo" desde Santiago el 2 de septiembre de 1845.

\section{Conclusiones}

Las cartas fueron cruciales vehiculizadores de la literatura de la época y testimonios culturales del "desborde afectivo del paradigma romántico" (Peluffo, 2016: 27). También revelan la red de ayuda recíproca dentro de la comunidad de intelectuales de 1837, socialistas, exiliados y perseguidos políticos en nuestro país. Tomando en cuenta algunas ideas del giro afectivo (Ahmed, Rosenwein, Macón) y la idea de red (Maíz, Fernández Bravo), este artículo ha revisado algunos sentimientos prestigiados y cierto reparto de roles y posicionamientos diferenciales dentro de la comunidad emocional de la Generación de 1837 que puede reconstruirse - acaso conjeturarse- a partir del epistolario de uno de sus protagonistas, Juan María Gutiérrez. No es difícil constatar la centralidad de los sentimientos en estas cartas: aún no culturalmente feminizados, el cariño y amor entre hombres circulan de una epístola a otra con recurrencia y espontaneidad. En todas ellas aparece tematizado, expresa o implícitamente, el modo en que los vínculos amistosos y literarios los han ayudado a combatir el dolor del exilio, otro de los sentimientos recurrentes en estas cartas. 
El lugar que Gutiérrez se labra a sí mismo es el de crítico y antologador, frente al Echeverría, venerado y (auto)considerado la voz de la nueva y "verdadera" poesía americana. Así, según hemos visto, el afecto del fundador de la América Poética hacia Echeverría se construye a partir de la idolatría, la admiración, la temprana certeza de que el amigo es el apóstol de esa generación. Por el contrario, la expresión del afecto en Mármol y en Sarmiento se presenta siempre asociada al pedido de gestiones en torno a sus obras. Las cartas de Mármol revelan su apelación constante al humor entremezclado con la amistad como modos de morigerar o de disculparse ante sus pedidos. El tono de Sarmiento, en cambio, está signado por la ironía, por cierto desprecio hacia las actividades de su interlocutor, y sus expresiones de afecto parecen dirigidas a un único objetivo: lograr —exigir- que Gutiérrez trabaje para difundir su Facundo.

Estas cuarenta cartas, escritas (casi todas) entre 1837 y 1852, dejan ver lo inseparables que han sido en las sensibilidades románticas de estos jóvenes lo afectivo, lo literario y lo político. Se trataba de un mismo caldo, personal pero ante todo social y culturalmente determinado, de "afecciones razonadas" (Varela, T. II: 32). 


\section{Bibliografía}

» Achugar, H. (1998). Parnasos fundacionales. Letra, nación y Estado en el siglo XIX. En Achugar, H.; D'Alessandro, S.; Hernández, M. C. y Poch, S. (comps.). La fundación por la palabra. Letra y Nación en América Latina en el Siglo XIX. Montevideo, Universidad de la República, FHCE.

» Ahmed, S. (2004). Cultural Politics of Emotions. Londres, Routledge.

»----. (2010). The Promise of Happiness. Durham, Duke University Press.

» Amante, A. (2010). Poéticas y políticas del destierro. Argentinos en Brasil en la época de Rosas. Buenos Aires, FCE.

» Archivo del Doctor Juan María Gutiérrez. Epistolario (1979). Tomos I y II. Moglia, R. y García, M. (eds.). Buenos Aires, Biblioteca del Congreso de la Nación.

"Arfuch, L. (2015). El “giro afectivo”. Emociones, subjetividad y política. En De Signis, núm. 24.

" Armon-Jones, C. (1986). The Social Functions of Emotion. En Harré, R. (ed.). The Social Construction of Emotions. Oxford, Basil Blackwell.

"Arnoux, M. (2016). La escritura epistolar. Cartas de Josefa Gómez a Juan Bautista Alberdi en tiempos de la guerra del Paraguay. En Traslaciones, núm. 3, vol. 6.

»Batticuore, G. (2005). Modalidades y fantasmas de la autoría femenina. Publicistas y literatas. En La mujer romántica. Lectoras, autoras y escritores en la Argentina 1830-1870. Buenos Aires, Edhasa.

»Barrán, J. P. (1989). Historia de la sensibilidad en el Uruguay, t. II. Montevideo, EBO.

"Chartier, R. (1993). Los secretarios. Modelos y prácticas epistolares. En Libros, lecturas y lectores en la Edad Moderna. Madrid, Alianza.

"Crespo, N. (2018). “Un corazón porteño": las cartas de Florencio Varela a Juan María Gutiérrez (1833-1842). En Landa. Revista do Núcleo Onetti de Estudos Literários Latino-Americanos, núm. 6, vol. 2, pp. 199-219.

»----. (2019). La trama epistolar de la América Poética. En Cuadernos del CILHA, núm. 20, vol. 31, pp.15-38.

》Derrida, J. (1998). Políticas de la amistad. Madrid, Trotta.

»Elias, N. (2012 [1939]). El proceso de la civilización. Investigaciones sociogenéticas y psicogenéticas. García Cotarelo, R. (trad.). Zabludovsky, G. (prefacio). México, FCE.

" Goldman, N. (2008). Lenguaje y revolución. Conceptos políticos clave en el Río de la Plata, 1780-1850. Buenos Aires, Prometeo.

"González Bernaldo de Quirós, P. (2008). Civilidad y política en los orígenes de la nación argentina. Las sociabilidades en Buenos Aires, 1829-1862. Buenos Aires, FCE.

» Iglesia, C. (1999). Contingencias de la intimidad; reconstrucción epistolar de la familia en el exilio. En Devoto, F. y Madero, M. (eds.). Historia de la vida privada en la Argentina, T. 1 País antiguo. De la colonia a 1870. Buenos Aires, Taurus.

»----. (2014). Echeverría: la patria literaria. En Iglesia, C. y El Jaber, L. (dirs. del 
vol.). Jitrik, N. (dir. gral.). Historia crítica de la literatura argentina, T. I. Una patria literaria. Buenos Aires, Emecé.

" Janik, D. (2000). Periodismo y literatura: su alianza en la época de la Independencia bajo el signo de la llustración (Argentina, Chile, Colombia). En Acta Literaria, vol. 25. En línea: https://www.redalyc.org/articulo.oa?id=23702505

"Macón, C. (2013). SENTIMUS ERGO SUMUS. El surgimiento del "giro afectivo" y su impacto sobre la filosofía política. En Revista Latinoamericana de Filosofía Política, núm. 2, vol. 6.

" Maíz, C. (2014). Las re(d)vistas latinoamericanas y las tramas culturales: Redes de difusión en el romanticismo y el modernismo. En Cuadernos del CILHA, núm. 12, vol.14.

" Maíz, C. y Fernández Bravo, Á. (2009). Episodios en la formación de redes culturales en América Latina. Buenos Aires, Prometeo.

" Myers, J. (2005). Los universos culturales del Romanticismo. Reflexiones en torno a un objeto oscuro. En Batticuore, G.; Gallo, K. y Myers, J. (comps.). Resonancias románticas. Ensayos sobre historia de la cultura argentina (1820-1890). Buenos Aires, Eudeba. pp. 15-46.

"----. (2011). Orden y virtud. El discurso republicano en el régimen rosista. Bernal, Universidad Nacional de Quilmes.

»Pagliai, L. (2013). Génesis textual y pragmática del discurso en la escritura epistolar: reflexiones teórico- metodológicas. En Políticas de la Memoria, Anuario de investigación e información del CeDlinCi, núm.14.

»Peluffo, A. (2016). En clave emocional. Cultura y afecto en América Latina. Buenos Aires, Prometeo.

"Prochasson, C. (1993). Les intellectuels, le socialismo et la guerre. París, Seuil.

»Rosenwein, B. (2006). Emotional Communities in the Early Middle Ages. Nueva York, Cornell University Press.

"Scheff, T. (1997). Emotions, the Social Bond, and Human Reality: Part/Whole Analysis. Cambridge, Cambridge University Press.

» Tarcus, H. (2016). El socialismo romántico en el Río de la Plata (1837-1852). Buenos Aires, FCE.

"Viñas, D. (1974). Literatura argentina y realidad política. De Sarmiento a Cortázar. Buenos Aires, Siglo XX.

»Wasserman, F. (2008). Entre Clio y la Polis. Conocimiento histórico y representaciones del pasado en el Río de la Plata (1830-1860). Buenos Aires, Teseo.

"Weinberg, F. (1977). El Salón Literario de 1837. Buenos Aires, Hachette.

"Williams, R. (1980). Estructuras del sentir. En Marxismo y literatura. Di Masso, P. (trad.). Barcelona, Península. pp. 150-158. 
